Harvard Medical School, Boston, MA USA

Correspondence to: J K Silver julie_silver@hms.harvard.edu Cite this as: BMJ 2021;375:n2381 http://dx.doi.org/10.1136/bmj.n2381 Published: 06 October 2021

\section{Women sidelined in pandemic research}

\author{
The time they've lost is gone forever
}

Grace C Huang, Julie K Silver

Many experts predict that the covid-19 pandemic will set back progress for women in the workforce by perhaps as much as two decades. ${ }^{12}$ Women comprise the majority of healthcare workers in many countries, and for those in academic medicine, a large body of literature shows widespread gender disparities in leadership opportunities, compensation, and advancement, ${ }^{3-6}$ which have worsened since the pandemic. $^{78}$

The study by Gayet-Ageron and colleagues(doi:10.1136/bmj.n2288) ${ }^{9}$ adds to the burgeoning evidence on gender inequities in publishing. ${ }^{10-13}$ The study group compared the representation of women in key authorship roles in the two years before the pandemic (January 2018 to December 2019) and during the pandemic (January 2020 to May 2021), examining more than 63000 manuscripts submitted to 11 BMJ Publishing Group journals (nine specialist, two general medicine). Manuscript types included original research and systematic reviews and were categorized by whether the topic of research was related to covid-19 or not. The major finding was that the frequency of prominent authorship roles, defined by first, last, or corresponding author positions, worsened for women during the pandemic. Manuscripts related to covid-19 also had lower levels of women authorship of all types, including coauthorship.

Findings showing gender disparities in publishing, while disturbing, are wholly unsurprising. Data from preprint servers showed early signs, with decreased submission rates among women. ${ }^{14}$ As schools converted to virtual formats or shuttered altogether, and childcare workers were limited by lockdowns, a parenting crisis arose globally. This impacted women disproportionately, since they tend to have a higher share of household responsibilities than men. ${ }^{15}$

Gayet-Ageron and colleagues shine a light on prominent authorship of covid-19 specific publications, showing that the critically important contributions of women physicians and scientists were marginalized in what might be considered the most consequential scientific topic of the century. Nuanced inequalities also manifested in Gayet-Ageron and colleagues' study; for example, the more authors there were on a covid-19 related manuscript, the less likely it was that a woman would be the last or corresponding author.

Although prominent authorship for women improved over some periods, it would be naïve to interpret these trends as "catching up," given that all academic work requires lead time to develop collaborations, secure funding, or obtain research ethical approval, before a study even begins. Similarly, career trajectories can be accelerated by early gains. For example, the Hirsch index (H-index) is a commonly used metric for research productivity that influences academic rank promotion, and women who missed an opportunity during the pandemic have forever lost the "compounded interest" associated with it. We can anticipate that current $\mathrm{H}$-index disparities might be exacerbated in the future, and more profoundly affect women early in their careers. ${ }^{16}$

This study expands the time and space horizon on the pandemic's impact on scholarship beyond the initial global outbreak-treating the pandemic era as a multiphasic and multiregional phenomenon. As acknowledged by the authors, gender identity was treated as binary and through imperfect algorithms for gender determination. And although the journals were identified from an international community of scholars, the findings might differ among specialties more heavily populated by women or among journals less well established than those selected. Women with intersectional identities (for example, those who identify with ethnic minority groups or as sexual or gender minorities) often face compounded bias and discrimination.

Yet the question remains unanswered: what will governments, healthcare institutions, corporations, and communities do to better support women physicians and scientists? The literature offers solutions with global applicability. For example, a recent systematic review of 91 studies from six continents identified effective interventions to advance women in medicine, organized into the categories of organizational processes (work-life integration, elimination of gender bias), awareness and engagement (fostering awareness of inclusion and diversity, developing a culture of improvement), mentoring and networking, leader training and development, and support tools (to improve recruitment, retention, and promotion). ${ }^{17}$ This evidence based assessment emphasizes how organizations can change, rather than focusing on how women should change.

The evidence on gender inequities in academic medicine varies only by the magnitude of measured differences and the settings in which they have been found. The aftershocks of the covid-19 pandemic's effects on women will result not only in lost time for those women but in lost scientific discoveries. There is a pressing need to support them. The urgent responsibility for intervention sits firmly on the shoulders of leaders in healthcare, government, business, and the wider community. Quickly finding new and better ways to support women in medicine and science is a win for every stakeholder, which means a win for everyone. 
Competing interests: We have read and understood the BMJ Group policy on declaration of interests and declare the following interests: GH owns stock in Pfizer.

Provenance and peer review: Commissioned; not externally peer reviewed.

1 Kashen J, Glynn SJ, Novello A. How COVID-19 sent women's workforce progress backward. Center for American Progress. 2020 Oct 30;30. Accessed on Sept 27, 2021. https://www.americanprogress.org/issues/women/reports/2020/10/30/492582/covid-19-sent-womens-workforceprogress-backward/

2 Blaskó Z, Papadimitriou E, Manca AR. How will the COVID-19 crisis affect existing gender divides in Europe? Publications Office of the European Union, 2020, https://publications.jrc.ec.europa.eu/repository/handle/JRC120525, Accessed on Sept 27, 2021.

3 Hoff T, Lee DR. The gender pay gap in medicine: A systematic review. Health Care Manage Rev 2021;46:E37-49.pmid: 33534271

4 Laver KE, Prichard IJ, Cations M, Osenk I, Govin K, Coveney JD. A systematic review of interventions to support the careers of women in academic medicine and other disciplines. BMJ Open 2018;8:e020380. doi: 10.1136/bmjopen-2017-020380. pmid: 29572397

5 Mousa M, Boyle J, Skouteris H, etal. Advancing women in healthcare leadership: A systematic review and meta-synthesis of multi-sector evidence on organisational interventions. EClinicalMedicine 2021;39:101084. doi: 10.1016/j.eclinm.2021.101084. pmid: 34430838

6 Richter KP, Clark L, Wick JA, etal. Women Physicians and Promotion in Academic Medicine. N Engl J Med 2020;383:2148-57. doi: 10.1056/NEJMsa1916935. pmid: 33252871

7 Dahlberg ML, Higginbotham E, eds. National Academies of Sciences, Engineering, and Medicine; Policy and Global Affairs; Committee on Women in Science, Engineering, and Medicine; Committee on Investigating the Potential Impacts of COVID-19 on the Careers of Women in Academic Science, Engineering, and Medicine. The Impact of COVID-19 on the Careers of Women in Academic Sciences, Engineering, and Medicine. National Academies Press (US), 2021 Mar 9.

8 Silver JK, Larson AR, Jagsi R. COVID-19 and the effect on the gender pay gap in medicine. The BMJ Opinion. July 31, 2020. Accessed on September 27, 2021.

https://blogs.bmj.com/bmi/2020/07/31/covid-19-and-the-effect-on-compensation-and-financialstress-for-women-in-medicine/

9 Gayet-Ageron A, Ben Messaoud K, Richards M, Schroter S. Female authorship of covid-19 research in manuscripts submitted to 11 biomedical journals: cross sectional study. BMJ 2021;375:n2288.

10 Ha GL, Lehrer EJ, Wang M, Holliday E, Jagsi R, Zaorsky NG. Sex Differences in Academic Productivity Across Academic Ranks and Specialties in Academic Medicine: A Systematic Review and Meta-analysis. JAMA Netw Open 2021;4:e2112404. doi: 10.1001/jamanetworkopen.2021.12404. pmid: 34185071

11 Bendels MHK, Müller R, Brueggmann D, Groneberg DA. Gender disparities in high-quality research revealed by Nature Index journals. PLoS One 2018;13:e0189136. doi: 10.1371/journal.pone.0189136. pmid: 29293499

12 Pinho-Gomes AC, Peters S, Thompson K, etal. Where are the women? Gender inequalities in COVID-19 research authorship. BMJ Glob Health 2020;5:e002922. doi: 10.1136/bmigh-2020-002922. pmid: 32527733

13 Lerchenmüller C, Schmallenbach L, Jena AB, Lerchenmueller MJ. Longitudinal analyses of gender differences in first authorship publications related to COVID-19. BMJ Open 2021;11:e045176. doi: 10.1136/bmjopen-2020-045176. pmid: 33820790

14 Wehner MR, Li Y, Nead KT. Comparison of the Proportions of Female and Male Corresponding Authors in Preprint Research Repositories Before and During the COVID-19 Pandemic. JAMA Netw Open2020;3:e2020335. doi: 10.1001/jamanetworkopen.2020.20335. pmid: 32940678

15 Chesak SS, Yngve KC, Taylor JM, Voth ER, Bhagra A. Challenges and Solutions for Physician Mothers: A Critical Review of the Literature. Mayo Clin Proc 2021;96:1578-91. doi: 10.1016/j.mayocp.2020.10.008. pmid: 33840524

16 Ha GL, Lehrer EJ, Wang M, Holliday E, Jagsi R, Zaorsky NG. Sex Differences in Academic Productivity Across Academic Ranks and Specialties in Academic Medicine: A Systematic Review and Meta-analysis. JAMA Netw Open 2021;4:e2112404. doi: 10.1001/jamanetworkopen.2021.12404. pmid: 34185071

17 Mousa M, Boyle J, Skouteris H, etal. Advancing women in healthcare leadership: A systematic review and meta-synthesis of multi-sector evidence on organisational interventions. EClinicalMedicine 2021;39:101084. doi: 10.1016/j.eclinm.2021.101084. pmid: 34430838 